\title{
Evaluation of the use of an induced puripotent stem cell sheet for the construction of tissue-engineered vascular grafts
}

\author{
Narutoshi Hibino, MD, PhD, Daniel R. Duncan, BS, Ani Nalbandian, BS, Tai Yi, MD, Yibing Qyang, PhD, \\ Toshiharu Shinoka, MD, PhD, and Christopher K. Breuer, MD
}

\begin{abstract}
Objective: The development of a living, tissue-engineered vascular graft (TEVG) holds great promise for advancing the field of cardiovascular surgery. However, the ultimate source and time needed to procure these cells remain problematic. Induced puripotent stem (iPS) cells have recently been developed and have the potential for creating a pluripotent cell line from a patient's own somatic cells. In the present study, we evaluated the use of a sheet created from iPS cell-derived vascular cells as a potential source for the construction of TEVG.
\end{abstract}

\begin{abstract}
Methods: Male mouse iPS cells were differentiated into embryoid bodies using the hanging-drop method. Cell differentiation was confirmed by a decrease in the proportion of SSEA-1-positive cells over time using fluorescence-activated cell sorting. The expression of endothelial cell and smooth muscle cell markers was detected using real-time polymerase chain reaction (PCR). The differentiated iPS cell sheet was made using temperature-responsive dishes and then seeded onto a biodegradable scaffold composed of polyglycolic acid-poly-L-lactide and poly(L-lactide-co- $\varepsilon$-caprolactone) with a diameter of $0.8 \mathrm{~mm}$. These scaffolds were implanted as interposition grafts in the inferior vena cava of female severe combined immunodeficiency/beige mice $(\mathrm{n}=15)$. Graft function was serially monitored using ultrasonography. The grafts were analyzed at 1,4 , and 10 weeks with histologic examination and immunohistochemistry. The behavior of seeded differentiated iPS cells was tracked using Y-chromosome fluorescent in situ hybridization and SRY real-time PCR.
\end{abstract}

Results: All mice survived without thrombosis, aneurysm formation, graft rupture, or calcification. PCR evaluation of iPS cell sheets in vitro demonstrated increased expression of endothelial cell markers. Histologic evaluation of the grafts demonstrated endothelialization with von Willebrand factor and an inner layer with smooth muscle actin- and calponin-positive cells at 10 weeks. The number of seeded differentiated iPS cells was found to decrease over time using real-time PCR $(42.2 \%$ at 1 week, $10.4 \%$ at 4 weeks, $9.8 \%$ at 10 weeks). A fraction of the iPS cells were found to be Y-chromosome fluorescent positive at 1 week. No iPS cells were found to co-localize with von Willebrand factor or smooth muscle actin-positive cells at 10 weeks.

Conclusions: Differentiated iPS cells offer an alternative cell source for constructing TEVG. Seeded iPS cells exerted a paracrine effect to induce neotissue formation in the acute phase and were reduced in number by apoptosis at later time points. Sheet seeding of our TEVG represents a viable mode of iPS cell delivery over time. (J Thorac Cardiovasc Surg 2012;143:696-703)

Surgeons and scientists have studied tissue engineering as a method of creating blood vessel substitutes with the ability to repair, remodel, and grow. ${ }^{1}$ The development of

From the Section of Cardiac Surgery, Yale University School of Medicine, New Haven, Conn.

Supported by funding from National Institutes of Health grant BRP R01 HL069368 (to C. K. Brauer and T. Shinoka), American Heart Association Postdoctoral Fellowship (to N. Hibino), and Howard Hughes Medical Institute Medical Research Training Fellowship (to D. R. Duncan).

Disclosures: Authors have nothing to disclose with regard to commercial support. Read at the 91st Annual Meeting of The American Association for Thoracic Surgery, Philadelphia, Pennsylvania, May 7-11, 2011.

Received for publication May 9, 2011; revisions received June 13, 2011; accepted for publication June 28, 2011; available ahead of print Jan 13, 2012.

Address for reprints: Christopher K. Breuer, Section of Cardiac Surgery, Yale University School of Medicine, 10 Amistad Street, Amistad Building, Room 301C, New

Haven, CT 06510 (E-mail: Christopher.breuer@yale.edu).

$0022-5223 / \$ 36.00$

Copyright $₫ 2012$ Published by Elsevier Inc. on behalf of The American Association for Thoracic Surgery

doi:10.1016/j.jtcvs.2011.06.046 a tissue-engineered vascular graft (TEVG) with bone marrow-derived mononuclear cells, differentiated smooth muscle cells, or endothelial cells seeded onto a biodegradable tubular scaffold has resulted in living vascular conduits with properties that mimic those of a native vessel. ${ }^{2-5} \mathrm{We}$ translated this basic science research and performed the first clinical trial evaluating the use of TEVGs in congenital heart surgery. ${ }^{6}$ That pilot study demonstrated not only that was it feasible to successfully implant TEVGs in humans, but also that this technology was safe and efficacious. ${ }^{7,8}$

The ultimate source of the cells for seeding the TEVG, however, remains problematic. In addition, little is known about the mechanisms of seeded cell engraftment that underlie the formation of vascular neotissue in vivo. To explore the cellular and molecular mechanisms essential for neovessel formation, we developed a miniaturized version of the tissue-engineered scaffold used in our clinical study to enable TEVG implantation in a murine model. ${ }^{9}$ This model showed that seeded bone marrow mononuclear cells 


\section{Abbreviations and Acronyms \\ ESCs = embryonic stem cells \\ iPS = induced pluripotent stem \\ qRT- = quantitative reverse-transcriptase \\ PCR polymerase chain reaction \\ TEVG $=$ tissue-engineered vascular graft}

exerted a paracrine effect to induce neotissue formation and disappeared in the acute phase soon after implantation. Although bone marrow mononuclear cells were appropriate for TEVG creation in a low-pressure venous model, a stronger contribution of seeded cells seems to be required for appropriate neovessel formation in high-pressure systems.

Embryonic stem cells (ESCs) have the potential to differentiate into various cell types, and ESCs might provide a source of cells for seeding a variety of tissue engineering constructs. ${ }^{10}$ Because the clinical use of ESCs remains challenging owing to ethical and immunologic problems, induced pluripotent stem (iPS) cells were developed by inducing forced expression of certain stem cell-associated genes in nonpluripotent cells. ${ }^{11}$

In the present study, we sought to determine whether seeded iPS cells could differentiate into vascular neotissue and contribute to neovessel formation in a murine model.

\section{METHODS}

\section{Culture and Differentiation of iPS Cells}

iPS cells were purchased from RIKEN BioResource Center (Tokyo, Japan $)^{12}$ and maintained on mitomycin-treated embryonic feeders in Dulbecco's modified Eagle medium supplemented with $15 \%$ fetal bovine serum (ThermoScientific Hyclone, Logan, Utah), 2 mM L-glutamine, $0.1 \mathrm{mM}$ nonessential amino acids, $1 \mathrm{mM}$ sodium pyruvate, $0.1 \mathrm{mM}$ B-mercaptoethanol, $100 \mathrm{U} / \mathrm{mL}$ penicillin, $100 \mathrm{mg} / \mathrm{mL}$ streptomycin, and $1000 \mathrm{U} / \mathrm{mL}$ leukemia inhibitory factor. The cells were differentiated for 5 days as embryoid bodies formed in hanging drops of embryonic stem cell medium without leukemia inhibitory factor. At 5 days, the embryoid bodies were dissociated into single cells with $0.25 \%$ trypsin for 5 minutes at $37^{\circ} \mathrm{C} .{ }^{13}$

\section{Identification of Cell Differentiation}

Cell differentiation was confirmed by a decrease over time in the proportion of cells positive for SSEA-1 (R\&D Systems, Minneapolis, Minn) using fluorescence-activated cell sorting. The cells were acquired on a fluorescence-activated cell sorting Aria cell sorter (BD Biosciences, San Jose, Calif), and the results were analyzed using DIVA software (BD Bioscience). The expression of endothelial cell and smooth muscle cell markers was detected using real-time quantitative reverse-transcriptase polymerase chain reaction (qRT-PCR). RNA extraction from the explanted scaffold was performed with an RNeasy Mini Kit (Qiagen, Valencia, Calif) according to the manufacturer's protocol. Predesigned and validated genespecific TaqMan Gene Expression Assays from Applied Biosystems (Life Technologies, Foster City, Calif) were used in duplicate for qRTPCR according to the manufacturer's protocol. The genes of interest for analysis were calponin, platelet-endothelial cell adhesion molecule-1, vascular endothelial growth factor, and E-cadherin. qRT-PCR was performed in 96-well reaction plates using the iCycler iQ Real-Time PCR Detection
System (Bio-Rad, Hercules, Calif). Each qRT-PCR reaction consisted of the following steps: 2 minutes of uracil-N-glycosylase incubation at $50^{\circ} \mathrm{C}$ to remove possible amplicon contamination, followed by 10 minutes at $95^{\circ} \mathrm{C}$ to activate the polymerase, and 40 cycles of 15 seconds denaturing at $95^{\circ} \mathrm{C}$, and 1 minute at $60^{\circ} \mathrm{C}$ of extension and annealing. The data were collected at the end of each elongation step and analyzed with the iCycler iQ Real Time Detection System Software (Bio-Rad). Hypoxanthine-guanine phosphoribosyltransferase was used as an endogenous control.

\section{Creation of iPS Cell Sheet-Seeded TEVG}

iPS Cell sheet fabrication. The differentiated iPS cell sheet was made using temperature-responsive dishes (Cellseed, Tokyo, Japan) and then seeded onto a biodegradable scaffold composed of polyglycolic acid-poly-L-lactide and poly(L-lactide-co- $\varepsilon$-caprolactone) with a diameter of $0.8 \mathrm{~mm}$

Scaffold fabrication. The scaffolds were constructed from a nonwoven polyglycolic acid mesh (Concordia Fibers, Coventry, RI) and a copolymer sealant solution of poly-L-lactide and poly(L-lactide-co- $\varepsilon$-caprolactone using the dual cylinder chamber molding system, as previously described. ${ }^{9}$ TEVG implantation. TEVG implantations were performed using microsurgical technique. The scaffolds were inserted into the infrarenal inferior vena cavas of 3- to 4-month-old, female severe combined immunodeficiency/beige mice (Jackson Laboratories, Bar Harbor, Maine), as previously described. ${ }^{9}$ A total of 15 mice were implanted with TEVG. All animal experiments were done in accordance with the institutional guidelines for the use and care of animals, and the institutional review board approved the experimental procedures described.

\section{Ultrasonography}

Serial ultrasound scans (Vevo Visualsonics, Toronto, Canada) were used for graft surveillance in both the seeded and the unseeded groups. Before ultrasonography, the mice were anesthetized with $1.5 \%$ inhaled isoflurane.

\section{Histologic Analysis}

The grafts were analyzed at 1,4 , and 10 weeks with histologic examination and immunohistochemistry.

Histologic examination. The explanted grafts were pressure fixed in $10 \%$ formalin overnight and then embedded in paraffin or glycolmethacrylate using previously published methods. ${ }^{9}$ The sections were stained with hematoxylin and eosin.

Immunohistochemistry. The primary antibodies included mouseanti-human smooth muscle actin (Dako, Carpinteria, Calif) and rabbit-antihuman von Willebrand factor (Dako), both of which have crossreactivity with mouse. Antibody binding was detected using a goat-anti-rabbit IgG-Alexa Fluor 488 or a goat-anti-mouse IgG-Alexa Fluor 488 (Invitrogen, Carlsbad, Calif).

\section{iPS Cell Quantification Using Real-Time qRT-PCR}

Explanted tissue grafts were frozen in OCT compound and each sectioned into 40 sections of $10 \mu \mathrm{m}$ using Cryocut 1800 (Leica, Buffalo Grove, III). Excess OCT compound was removed by centrifugation in water. After tissue digestion, DNA was isolated from samples using the DNeasy Blood and Tissue Kit (Qiagen) according to the manufacturer's instructions. Validated gene-specific TaqMan Gene Expression Assays from Applied Biosystem (Foster City, Calif) predesigned to amplify the SRY gene were used in duplicate for qRT- PCR according to the manufacturer's protocol. DNA amplification and quantification was performed using the iCycler iQ Real-Time PCR Detection System (Bio-Rad). Each qRT-PCR reaction consisted of the following steps: 2 minutes of uracil-N-glycosylase incubation at $50^{\circ} \mathrm{C}$ to remove possible amplicon contamination, followed by 10 minutes at $95^{\circ} \mathrm{C}$ to activate the polymerase, and 40 cycles of 15 seconds denaturing at $95^{\circ} \mathrm{C}$ and 1 minute at $60^{\circ} \mathrm{C}$ of extension and annealing. The data were 
collected at the end of each elongation step and analyzed with iCycler iQ Real Time Detection System Software (Bio-Rad). The percentage of $Y$ chromosome-positive cells remaining on the graft were then determined using quantification of SRY DNA content, as previously described, ${ }^{14}$ taking advantage of the male iPS cell-seeded TEVGs having been implanted into female mice.

Y-chromosome fluorescent in situ hybridization/terminal deoxynucleotidyl transferase dUTP nick end label-

ing staining. Fluorescent in situ hybridization was performed on paraffin sections using digoxigenin-labeled mouse Y-chromosome probe detected with a Rhodamine-conjugated antibody to digoxigenin (Roche Diagnostics, Mannheim, Germany), as previously described. ${ }^{15,16}$ Terminal deoxynucleotidyl transferase dUTP nick end labeling (TUNEL) staining was performed using the DeadEnd Fluorometric TUNEL System kit according to the manufacturer's instructions (Promega, Madison, WI). Combined fluorescent in situ hybridization/TUNEL was performed by completing the TUNEL protocol, starting with the equilibration buffer step after anti-digoxigenin hybridization. Image acquisition was performed using a Leica SP5 confocal microscope (Leica Microsystems, Wetzlar, Germany).

\section{Statistical Analysis}

Statistical differences were measured using Student's $t$ test or analysis of variance. $P<.05$ was considered statistically significant.

\section{RESULTS}

The differentiation of iPS cells in vitro was confirmed using cell surface markers. Fluorescence-activated cell sorting analysis of the iPS cells demonstrated that the ratio of undifferentiated SSEA-1-positive cells decreased over time after switching to differentiation medium (day $0,81.0 \%$; day 10 , $28.7 \%$; day $20,4.3 \%$; Figure $1, A$ ). Concurrently, these differentiated cells expressed endothelial cell markers, including vascular endothelial growth factor, platelet-endothelial cell adhesion molecule-1, and E-cadherin, and the smooth muscle cell marker calponin (Figure 1, B).

Next, to identify the proper conditions for cell attachment to the scaffold, 5 million differentiated iPS cells were seeded onto the graft by manual pipetting. The number of attached cells and the seeding efficiency were then measured over time. No significant difference was found in the attached cell number and seeding efficiency at 1,3 , and 7 days (seeding efficiency: 1 day, $6.5 \% \pm$ $0.8 \% ; 3$ days, $7.6 \% \pm 2.5 \% ; 7$ days, $8.6 \% \pm 2.5 \%$; Figure 2). Because the seeding efficiency was very low, regardless of the incubation period, we developed a new seeding method using a sheet of differentiated iPS cells wrapped around the scaffold to seed cells more effectively. This new method using an iPS cell sheet significantly improved the seeding efficiency compared with traditional pipette seeding (sheet, $86.5 \% \pm 11.8 \%$; traditional, $4.9 \% \pm 1.5 \%$; Figure 3 ).

After implantation of this differentiated iPS cell sheetseeded scaffold, all mice survived without thrombosis, aneurysm formation, graft rupture, or calcification. Ultrasonography showed patent grafts at 10 weeks (Figure 4, $E)$. Histologic evaluation of the grafts demonstrated endothelialization with von Willebrand factor and an inner layer with smooth muscle actin-positive cells at 10 weeks (Figure 4, C, D). Because the male iPS cell-seeded graft was implanted into female mice, the seeded cells were identified using Y-chromosome fluorescent in situ hybridization. Some seeded cells remained on the outer layer of the graft at 1 week after implantation. At 4 weeks, very small numbers of seeded cells were found. The number of seeded differentiated iPS cells quantified by realtime PCR decreased dramatically over time (1 week, $42.2 \%$; 4 weeks, $10.4 \%$; 10 weeks, 9.8\%; Figure 5). A fraction of the iPS cells was found to be TUNEL positive at 1 week (Figure 6). No iPS cells were co-localized with von Willebrand factor or smooth muscle actin-positive cells at 10 weeks. We also found teratoma formation in 1 of 5 mice at 10 weeks.

\section{DISCUSSION}

In the present study, we demonstrated the feasibility of using a differentiated iPS cell sheet as an alternative cell source for TEVG creation. Most of the seeded iPS cells disappeared as a result of apoptosis at later points, suggesting
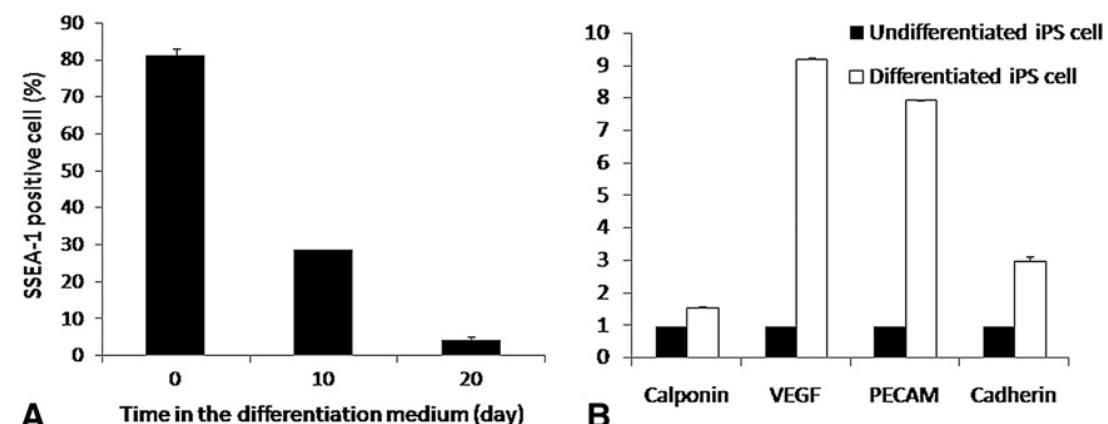

FIGURE 1. Confirmation of differentiation of induced pluripotent stem ( $i P S$ ) cells in vitro. A, Ratio of undifferentiated SSEA-1-positive cells by fluorescence-activated cell sorting analysis decreased over time after changing to differentiation medium. B, Expression of endothelial markers (vascular endothelial growth factor [VEGF], platelet-endothelial cell adhesion molecule-1 [PECAM], and E-cadherin) and smooth muscle cell marker (calponin) in differentiated iPS cells. 

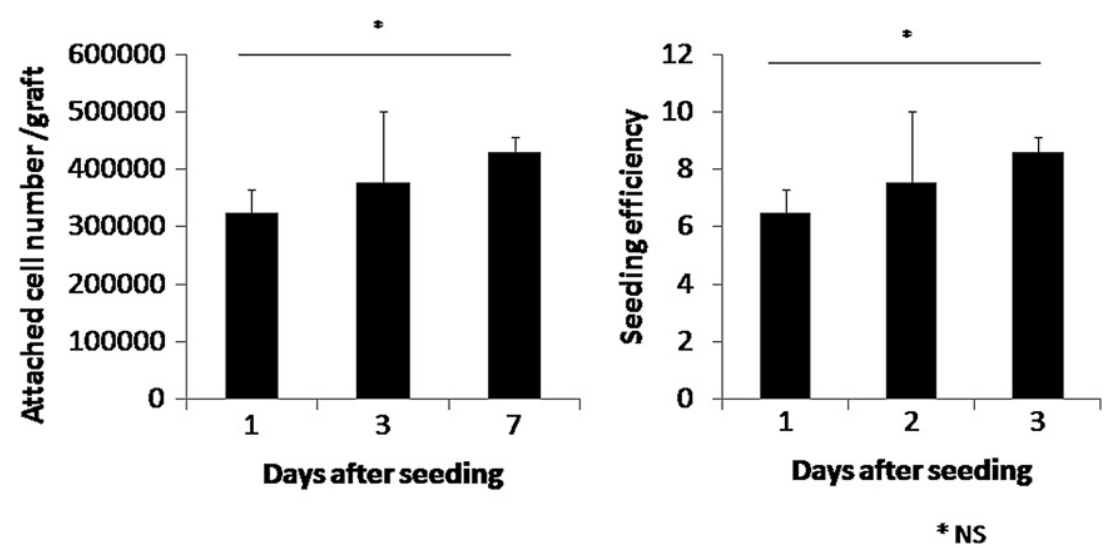

FIGURE 2. Attached cell number and seeding efficiency of differentiated induced pluripotent stem (iPS) cells seeded onto the scaffold. No significant difference was found for any incubation period.

that seeded iPS cells exerted a paracrine effect to induce neotissue formation in the acute phase.

Cells are 1 of the key factors involved in vascular regeneration, and various cell types have been used for vascular tissue engineering. Stem cells or progenitor cells can differentiate into vascular cells that form new vessels or tissues. Mesenchymal stem cells ${ }^{17}$ and endothelial progenitor cells ${ }^{18}$ reside in the bone marrow and have been studied most for their vascular regeneration potential. Bone marrow-derived stem cells have undergone the most translational and human studies of all stem cell approaches. The clinical trials performed to date show little increased risk associated with their therapeutic use in humans. ${ }^{19,20}$
However, bone marrow-derived stem cell therapy has limitations. The typical surface markers used to isolate these stem cells result in a mixed population of cells that have not been completely characterized. ${ }^{21-24}$ In addition, in the patients who most need stem cell therapy, these cells are rare, have limited replicative capacity, and are often dysfunctional, especially in patients who have the conditions typically associated with vascular disease, such as older age and diabetes mellitus, which impair angiogenic functionality. ${ }^{21,25}$

Our previous studies have demonstrated the feasibility of creating TEVGs by seeding bone marrow mononuclear cells onto biodegradable tubular scaffolds. ${ }^{2,3}$ These cells

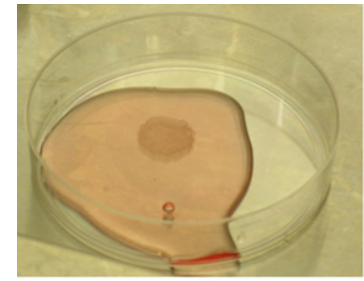

A

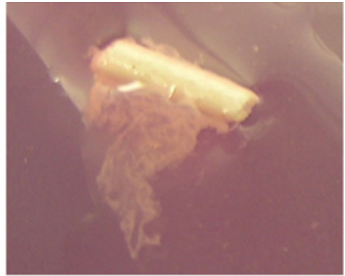

B
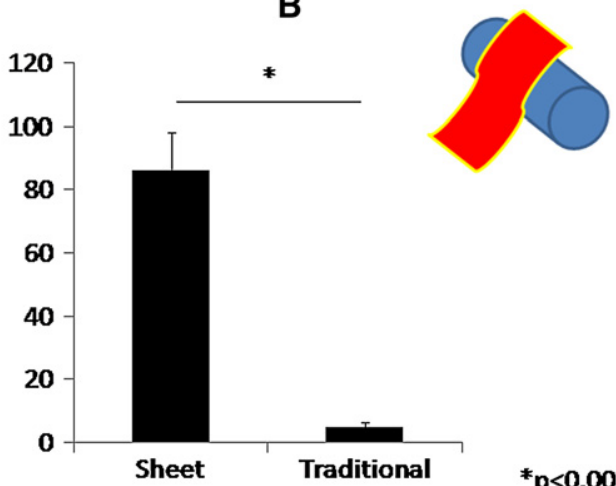

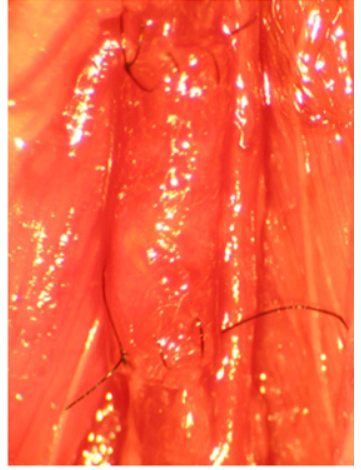

D

\section{C}

FIGURE 3. Differentiated induced pluripotent stem (iPS) cell sheet seeded tissue-engineered vascular graft (TEVG). A, Cell sheet creation from differentiated iPS cells. B, The scaffold was wrapped with this cell sheet for seeding. C, New seeding method using a differentiated iPS cell sheet significantly improved seeding efficiency compared with traditional pipette seeding. D, Differentiated iPS cell sheet seeded TEVG was implanted in mouse inferior vena cava. 


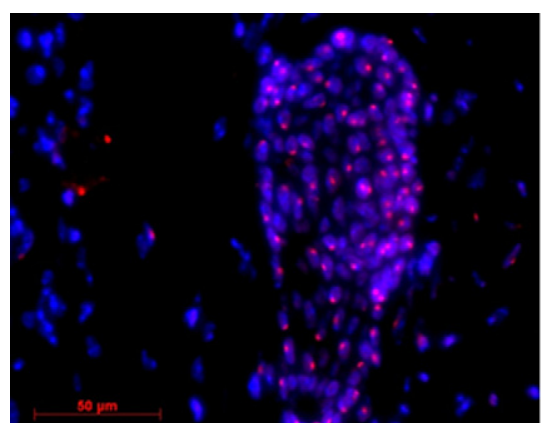

A

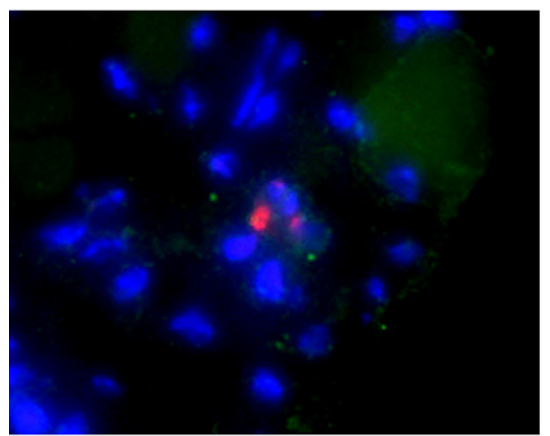

B

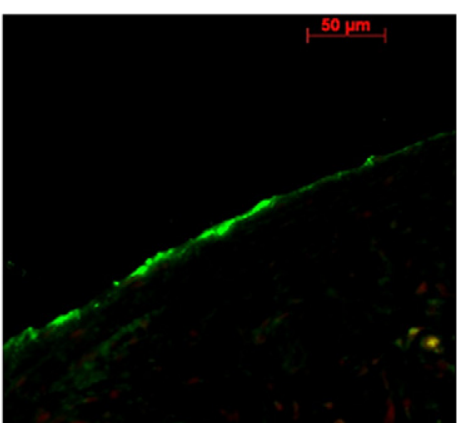

C

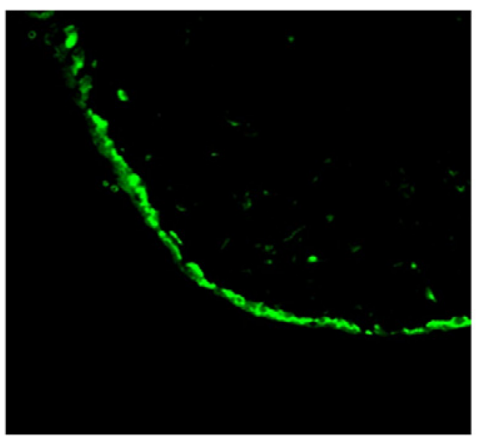

D

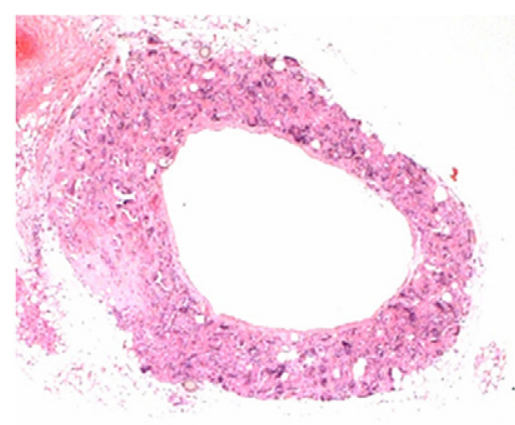

E

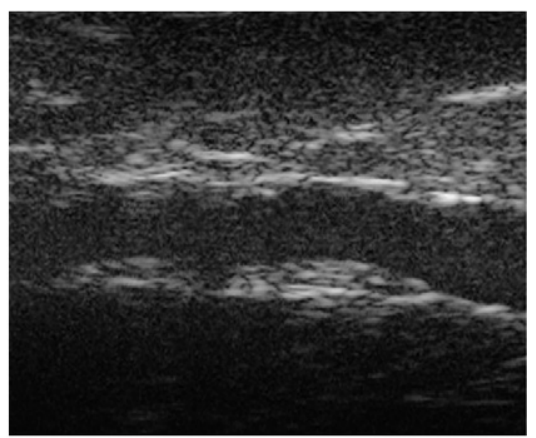

$\mathbf{F}$

FIGURE 4. Histologic examination of tissue-engineered vascular graft (TEVG). A, Seeded induced pluripotent stem ( $i P S)$ cells were identified as Y chromosome fluorescent in situ hybridization-positive cells (red) at 1 week after implantation (blue indicates DAPI). B, At 4 weeks, very small numbers of seeded cells were found. At 10 weeks, (C) endothelialization was present with von Willebrand factor (green) and (D) an inner layer with smooth muscle actin (green)-positive cells at 10 weeks. However, no Y chromosome fluorescent in situ hybridization-positive seeded iPS cells (red) were seen. E, Hematoxylin and eosin staining and $(\mathrm{F})$ ultrasonography showed patent graft at 10 weeks.

disappear rapidly after implantation and exert a paracrine effect to facilitate neotissue creation. ${ }^{26}$ In addition, we have shown that it takes 10 weeks for complete neovessel formation with endothelialization and smooth muscle layer creation. Compared with bone marrow-derived stem cells, ESCs have the advantage of pluripotentiality and greater proliferative capacity, suggesting they might be a useful source for cell seeding, but the clinical use of ESCs remains conflicted by ethical debate and immunologic barriers. As an alternative to ESCs, iPS cells are generated by inducing forced expression of certain stem cell-associated genes in nonpluripotent cells. ${ }^{1,27,28}$ iPS cells are similar to ESCs

\section{iPS cell \# after implantation}
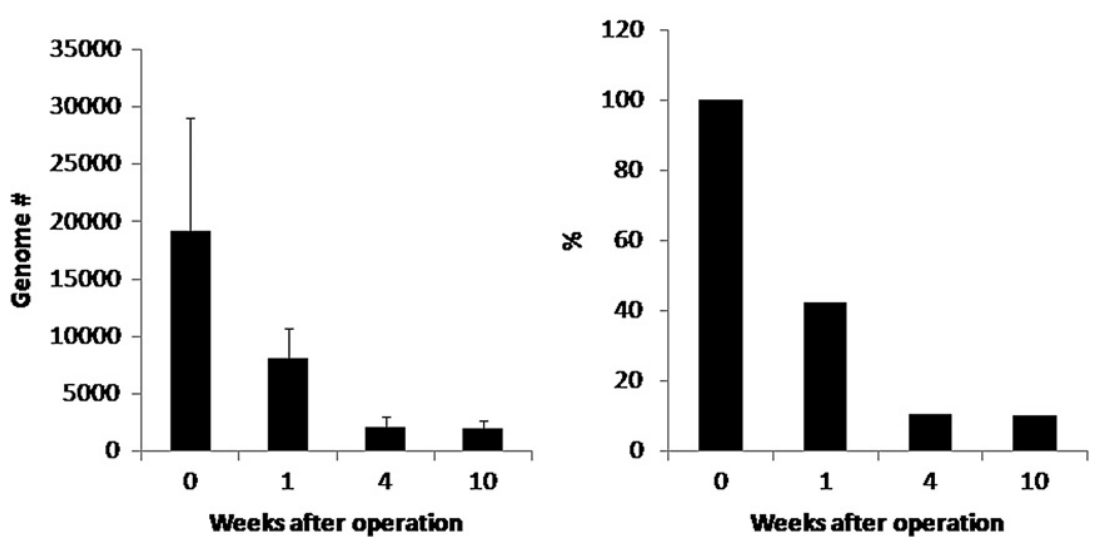

FIGURE 5. Quantification of seeded differentiated induced pluripotent stem (iPS) cells using real-time quantitative reverse transcriptase polymerase chain reaction $(P C R)$ using probe for SRY. Number of seeded iPS cells decreased dramatically over time. 


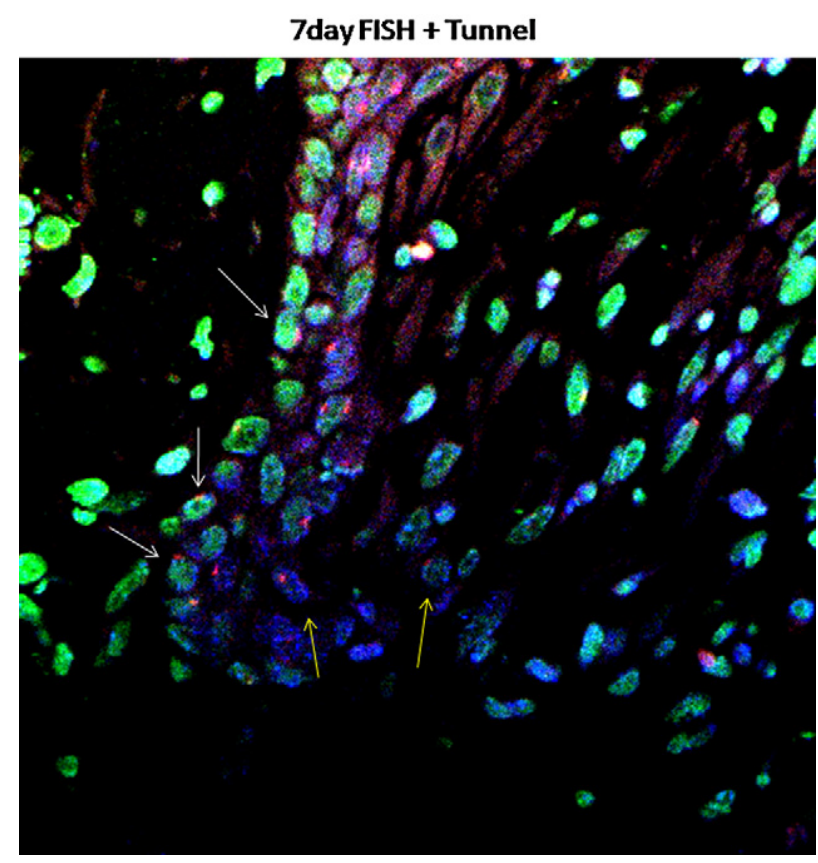

FIGURE 6. There was mixture of surviving (yellow arrows) and apoptotic (white arrows) seeded induced pluripotent stem (iPS) cells at 1 week after graft implantation (green indicates terminal deoxynucleotidyl transferase dUTP nick end labeling positive; red indicates SRY fluorescent in situ hybridization positive; and blue indicates DAPI).

in many respects and provide the potential to generate donor-specific pluripotent cells. Recent reports have shown that murine iPS cells can be differentiated into cardiovascular cells needed to repair heart and blood vessels and might represent a valuable cell source for vascular regeneration. $^{29,30}$ Therefore, we investigated the application of stem cell technology with the idea of creating a patient's own stem cells to promote earlier and better vascular neotissue formation.

Seeding methods for the delivery of iPS cells are diverse, and no method has been clearly shown to be superior in either promoting seeding efficiency or improving long-term graft function. ${ }^{31}$ To date, the most common method used in the construction of TEVGs is static seeding, in which a concentrated cell suspension is passively introduced onto a scaffold. This technique has several limitations that result in low efficiency seeding and minimal cell penetration of scaffold walls. As we demonstrated in the present study, the average seeding efficiency is around $10 \%$. Yang and colleagues, ${ }^{32}$ Sekine and colleagues, ${ }^{33}$ and Shimizu and colleagues ${ }^{34}$ developed a novel cell sheet system to engineer a graft that contracts in 3 dimensions. The technique to obtain a stable cell sheet was the use of temperature-responsive culture surfaces. A stable cell sheet of single-cell thickness can be harvested without losing the intercellular connections and then can be transferred to a second and third cell sheet. To increase the delivery of
iPS cells with our TEVG, we applied this cell sheet technology for differentiated iPS cells, and the seeding efficiency was found to be significantly improved.

Although the sheet seeding method led to a dramatic improvement in seeding efficiency, our results in vivo suggested that seeded iPS cells disappeared in the acute phase by apoptosis. Although the cell number remaining on the graft after implantation was greater than in our previous study, ${ }^{26}$ no engraftment of seeded cells was seen in our neovessels at 10 weeks. Some groups, however, have reported that seeded iPS cells can engraft with tissue in other models. In a study of rat arterial TEVGs fabricated with biodegradable tubular scaffolds and seeded with muscle-derived stem cells, the engraftment of seeded muscle-derived stem cells in the vascular tissue was identified by the direct comparison between the histologic findings and LacZ-positive seeded cell images. ${ }^{35}$ In a murine model of ischemic myocardium, transplanted endothelial cells differentiated from ESCs were tracked using bioluminescence imaging, which showed the persistence of the cells up to 8 weeks later. Echocardiography in that study revealed improved systolic function in hearts injected with ESC-ECs compared with vehicle. ${ }^{36}$ However, other groups have reported findings consistent with the results of our study. In a study of transplantation of human ESC-derived cardiomyocytes into ischemic murine myocardium, implanted cells died soon after transplantation into the infarcted heart. This problem was also found in other cell therapies for diabetes, ${ }^{37,38}$ Parkinson's disease, ${ }^{39,40}$ and muscular dystrophy. ${ }^{41,42}$ Because the death of these transplanted cells was multifactorial in origin, varied and complex interventions were required for the engraftment of cells in tissue. A cocktail of pro-survival factors, including matrigel and inhibitors of apoptosis, was proposed for targeting the key components of potential cell death pathways. ${ }^{43}$ Although the fate of seeded cells is controversial, the additional elucidation of pathways that cause iPS cell death would be an important next step to better understand and enhance the role of seeded iPS cells in the creation of improved TEVGs.

The heterogeneity inherent to the epigenetics and gene expression profiles of pluripotent cells raises concern for pleiotropic outcomes such as teratoma formation. ${ }^{44}$ Our study showed that teratomas formed in $25 \%$ of the grafts. To prevent the formation of teratomas, additional purification of differentiated iPS cells is required. Isolation using immunomagnetic beads or culture with growth factors such as vascular endothelial growth factor and plateletderived growth factor-BB are possible methods for improvement in purification. ${ }^{4,46}$ However, no method to properly direct this differentiation has yet been mastered. Studies have demonstrated that no growth factor causes differentiation along a single cell line, and, in contrast, differentiation has been shown to be spontaneous. ${ }^{47,48}$

In conclusion, differentiated iPS cells provide an alternative and attractive cell source for constructing TEVGs using 
the sheet engineering technique. Taking into consideration that the number of seeded iPS cells decreased over time as a result of apoptosis in the early phase, seeded iPS cells could work as a paracrine effect to induce neotissue formation in the acute phase. However, additional study such as cytokine arrays or microarrays is required to show the exact mechanism of paracrine effect. Some possibility of teratoma formation in the present differentiation method remains, representing a drawback for clinical applications of this approach. Additional study of the inhibition of apoptosis of seeded cells and the improvement in iPS cell purification procedures will enable the design and creation of the next generation of TEVGs.

The authors thank Lin Wang (Laboratory of Diane S. Krause) for assisting with $\mathrm{Y}$ chromosome fluorescent in situ hybridization analysis. The authors also thank RIKEN BioResource Center for providing iPS cells.

\section{References}

1. Goyal A, Wang Y, Su H, Dobrucki LW, Brennan M, Fong P, et al. Development of a model system for preliminary evaluation of tissue-engineered vascular conduits. J Pediatr Surg. 2006;41:787-91.

2. Brennan MP, Dardik A, Hibino N, Roh JD, Nelson GN, Papademitris X, et al. Tissue-engineered vascular grafts demonstrate evidence of growth and development when implanted in a juvenile animal model. Ann Surg. 2008;248:370-7.

3. Hibino N, Shin'oka T, Matsumura G, Ikada Y, Kurosawa H. The tissueengineered vascular graft using bone marrow without culture. J Thorac Cardiovasc Surg. 2005; 129:1064-70.

4. Shinoka T, Shum-Tim D, Ma PX, Tanel RE, Isogai N, Langer R, et al. Creation of viable pulmonary artery autografts through tissue engineering. J Thorac Cardiovasc Surg. 1998;115:536-46.

5. Matsumura G, Ishihara Y, Miyagawa-Tomita S, Ikada Y, Matsuda S, Kurosawa $\mathrm{H}$, et al. Evaluation of tissue-engineered vascular autografts. Tissue Eng. 2006;12:3075-83.

6. Shin'oka T, Imai Y, Ikada Y. Transplantation of a tissue-engineered pulmonary artery. N Engl J Med. 2001;344:532-3.

7. Hibino N, McGillicuddy E, Matsumura G, Ichihara Y, Naito Y, Breuer C, et al. Late-term results of tissue-engineered vascular grafts in humans. J Thorac Cardiovasc Surg. 2010;139:431-6. 6e1-2.

8. Shin'oka T, Matsumura G, Hibino N, Naito Y, Watanabe M, Konuma T, et al. Midterm clinical result of tissue-engineered vascular autografts seeded with autologous bone marrow cells. J Thorac Cardiovasc Surg. 2005;129:1330-8.

9. Roh JD, Nelson GN, Brennan MP, Mirensky TL, Yi T, Hazlett TF, et al. Smalldiameter biodegradable scaffolds for functional vascular tissue engineering in the mouse model. Biomaterials. 2008;29:1454-63.

10. Thomson JA, Itskovitz-Eldor J, Shapiro SS, Waknitz MA, Swiergiel JJ, Marshall VS, et al. Embryonic stem cell lines derived from human blastocysts. Science. 1998;282:1145-47.

11. Takahashi K, Tanabe K, Ohnuki M, Narita M, Ichisaka T, Tomoda K, et al. Induction of pluripotent stem cells from adult human fibroblasts by defined factors. Cell. 2007;131:861-72.

12. Okita K, Ichihara T, Yamanaka S. Generation of germline-competent induced pluripotent stem cells. Nature. 2007;448:313-7.

13. Moretti A, Caron L, Nakano A, Lam JT, Bernshausen A, Chen Y, et al. Multipotent embryonic isl1+ progenitor cells lead to cardiac, smooth muscle, and endothelial cell diversification. Cell. 2006;127:1151-65.

14. Zhong XY, Holzgreve W, Hahn S. Direct quantification of fetal cells in maternal blood by real-time PCR. Prenat Diagn. 2006;26:850-4.

15. Jones RJ, Collector MI, Barber JP, Vala MS, Fackler MJ, May WS, et al. Characterization of mouse lymphohematopoietic stem cells lacking spleen colonyforming activity. Blood. 1996;88:487-91.

16. Krause DS, Theise ND, Collector MI, Henegariu O, Hwang S, Gardner R, et al. Multi-organ, multi-lineage engraftment by a single bone marrow-derived stem cell. Cell. 2001;105:369-77.
17. Pittenger MF, Mackay AM, Beck SC, Jaiswal RK, Douglas R, Mosca JD, et al. Multilineage potential of adult human mesenchymal stem cells. Science. 1999; 284:143-7.

18. Khoo CP, Pozzilli P, Alison MR. Endothelial progenitor cells and their potential therapeutic applications. Regen Med. 2008;3:863-76.

19. Lunde K, Solheim S, Aakhus S, Arnesen H, Abdelnoor M, Egeland T, et al. Intracoronary injection of mononuclear bone marrow cells in acute myocardial infarction. N Engl J Med. 2006;355:1199-209.

20. Schachinger V, Erbs S, Elsasser A, Haberbosch W, Hambrecht R, Holschermann $\mathrm{H}$, et al. Intracoronary bone marrow-derived progenitor cells in acute myocardial infarction. $N$ Engl J Med. 2006;355:1210-21.

21. Asahara T, Kawamoto A. Endothelial progenitor cells for postnatal vasculogenesis. Am J Physiol Cell Physiol. 2004;287:C572-9.

22. Kalka C, Baumgartner I. Gene and stem cell therapy in peripheral arterial occlusive disease. Vasc Med. 2008;13:157-72.

23. Barber CL, Iruela-Arispe ML. The ever-elusive endothelial progenitor cell: identities, functions and clinical implications. Pediatr Res. 2006;59(4 Pt 2):26R-32R.

24. Brixius K, Funcke F, Graf C, Bloch W. Endothelial progenitor cells: a new target for the prevention of cardiovascular diseases. Eur J Cardiovasc Prev Rehabil. 2006;13:705-10.

25. Spinetti G, Kraenkel N, Emanueli C, Madeddu P. Diabetes and vessel wall remodelling: from mechanistic insights to regenerative therapies. Cardiovasc Res. 2008;78:265-73.

26. Roh JD, Sawh-Martinez R, Brennan MP, Jay SM, Devine L, Rao DA, et al. Tissue-engineered vascular grafts transform into mature blood vessels via an inflammation-mediated process of vascular remodeling. Proc Natl Acad Sci USA. 2010;107:4669-74.

27. Yu J, Vodyanik MA, Smuga-Otto K, Antosiewicz-Bourget J, Frane JL, Tian S, et al. Induced pluripotent stem cell lines derived from human somatic cells. Science. 2007;318:1917-20.

28. Park IH, Zhao R, West JA, Yabuuchi A, Huo H, Ince TA, et al. Reprogramming of human somatic cells to pluripotency with defined factors. Nature. 2008 10;451:141-46.

29. Schenke-Layland K, Rhodes KE, Angelis E, Butylkova Y, Heydarkhan-Hagvall S, Gekas C, et al. Reprogrammed mouse fibroblasts differentiate into cells of the cardiovascular and hematopoietic lineages. Stem Cells. 2008;26:1537-46.

30. Mauritz C, Schwanke K, Reppel M, Neef S, Katsirntaki K, Maier LS, et al. Generation of functional murine cardiac myocytes from induced pluripotent stem cells. Circulation. 2008;118:507-17.

31. Villalona GA, Udelsman B, Duncan DR, McGillicuddy E, Sawh-Martinez RF, Hibino $\mathrm{N}$, et al. Cell-seeding techniques in vascular tissue engineering. Tissue Eng Part B Rev. 2010;16:341-50.

32. Yang J, Yamato M, Shimizu T, Sekine H, Ohashi K, Kanzaki M, et al. Reconstruction of functional tissues with cell sheet engineering. Biomaterials. 2007; 28:5033-43.

33. Sekine H, Shimizu T, Yang J, Kobayashi E, Okano T. Pulsatile myocardial tubes fabricated with cell sheet engineering. Circulation. 2006;114(1 Suppl): I87-93.

34. Shimizu T, Yamato M, Isoi Y, Akutsu T, Setomaru T, Abe K, et al. Fabrication of pulsatile cardiac tissue grafts using a novel 3-dimensional cell sheet manipulation technique and temperature-responsive cell culture surfaces. Circ Res. 2002;90:e40.

35. Nieponice A, Soletti L, Guan J, Hong Y, Gharaibeh B, Maul TM, et al. In vivo assessment of a tissue-engineered vascular graft combining a biodegradable elastomeric scaffold and muscle-derived stem cells in a rat model. Tissue Eng Part A. 2010;16:1215-23.

36. Huang NF, Niiyama H, Peter C, De A, Natkunam Y, Fleissner F, et al. Embryonic stem cell-derived endothelial cells engraft into the ischemic hindlimb and restore perfusion. Arterioscler Thromb Vasc Biol. 2010;30:984-91.

37. Contreras JL, Bilbao G, Smyth CA, Eckhoff DE, Jiang XL, Jenkins S, et al. Cytoprotection of pancreatic islets before and early after transplantation using gene therapy. Kidney Int. 2002;61(1 Suppl):S79-84.

38. Nakano M, Matsumoto I, Sawada T, Ansite J, Oberbroeckling J, Zhang HJ, et al. Caspase- 3 inhibitor prevents apoptosis of human islets immediately after isolation and improves islet graft function. Pancreas. 2004;29:104-9.

39. Schierle GS, Hansson O, Leist M, Nicotera P, Widner H, Brundin P. Caspase inhibition reduces apoptosis and increases survival of nigral transplants. Nat Med. 1999;5:97-100.

40. Emgard M, Hallin U, Karlsson J, Bahr BA, Brundin P, Blomgren K. Both apoptosis and necrosis occur early after intracerebral grafting of ventral mesencephalic tissue: a role for protease activation. J Neurochem. 2003;86:1223-32. 
41. Guerette B, Skuk D, Celestin F, Huard C, Tardif F, Asselin I, et al. Prevention by anti-LFA-1 of acute myoblast death following transplantation. J Immunol. 1997; 159:2522-31.

42. Skuk D, Caron NJ, Goulet M, Roy B, Tremblay JP. Resetting the problem of cell death following muscle-derived cell transplantation: detection, dynamics and mechanisms. J Neuropathol Exp Neurol. 2003;62:951-67.

43. Laflamme MA, Chen KY, Naumova AV, Muskheli V, Fugate JA, Dupras SK, et al. Cardiomyocytes derived from human embryonic stem cells in prosurvival factors enhance function of infarcted rat hearts. Nat Biotechnol. 2007;25:1015-24

44. Segers VF, Lee RT. Stem-cell therapy for cardiac disease. Nature. 2008;451: 937-42.

45. Kehat I, Kenyagin-Karsenti D, Snir M, Segev H, Amit M, Gepstein A, et al. Human embryonic stem cells can differentiate into myocytes with structural and functional properties of cardiomyocytes. J Clin Invest. 2001;108:407-14.

46. Ferreira LS, Gerecht S, Shieh HF, Watson N, Rupnick MA, Dallabrida SM, et al. Vascular progenitor cells isolated from human embryonic stem cells give rise to endothelial and smooth muscle like cells and form vascular networks in vivo. Circ Res. 2007;101:286-94.

47. Schuldiner M, Yanuka O, Itskovitz-Eldor J, Melton DA, Benvenisty N. Effects of eight growth factors on the differentiation of cells derived from human embryonic stem cells. Proc Natl Acad Sci USA. 2000;97:11307-12.

48. Levenberg S, Golub JS, Amit M, Itskovitz-Eldor J, Langer R. Endothelial cells derived from human embryonic stem cells. Proc Natl Acad Sci USA. 2002;99: 4391-6.

\section{Discussion}

Dr John E. Mayer, Jr. (Boston, Mass). Congratulations on a very interesting study and on successfully overcoming the technical challenges of both the cell seeding problem and the implant of these tiny vascular grafts. Thank you for sending the manuscript and figures in advance.

I have a couple of specific questions and then a more general one. First of all, what was the thickness of the cell layers that were wrapped around the scaffolds? Do you think that nutrient diffusion limitations contributed to the apoptosis and the falling numbers of seeded cells in the grafts?

Dr Hibino. Thank you so much for your comment, Dr Mayer.

The thickness of the cell sheet is about $100 \mu \mathrm{m}$. Dr Okano's group, which developed this cell sheet technique, showed electrical coupling of double-layered neonatal rat cardiomyocyte sheets in vitro. They also reported 3-dimensinoal myocardial sheet tissue construction using 4-layer sheets in vivo. Based on these studies, our iPS sheet seems to have sufficient nutrient support by simple diffusion.

Dr Mayer. The second question is, do you know whether the cells that you have wrapped around your scaffold actually penetrate into the luminal surface before implant? If not, then you just had bare scaffold facing the bloodstream. How did you prevent thrombosis?

Dr Hibino. We did not examine the exact luminal penetration of the iPS cells, but the iPS cells should attach each other very strongly because other previous studies demonstrated there is a gap junction communication between the cells by the expression of connexin 43 in various cell types. In addition, our previous study using bone marrow mononuclear cell-seeded grafts demonstrated that our SCID/beige mouse model showed almost $100 \%$ patency even in the venous circulation because of the deficiency of the immune function and platelet function.

Dr Mayer. So did you use heparin or any other anticoagulants around the time of implant?

Dr Hibino. No, we did not use any anticoagulant.

Dr Mayer. Finally, the last questions, and the big questions really, are, first, how can we control the teratoma formation, and second, can you speculate on the specific paracrine effects that seem to be active here as opposed to there just being implantation cell effects?

Dr Hibino. Regarding the prevention of teratoma formation, enhanced purification of differentiated iPS cells would be the most important factor. So our collaborator at the Yale stem cell center is developing an improved method for this problem. They insert green fluorescent protein with a specific promoter gene to induce the differentiation to the vascular cell lineage and are then able to select green fluorescent protein-positive cells later.

Regarding the possible paracrine mechanism for neovessel formation, we are looking for the effect of specific cytokines such as transforming growth factor-beta, fibroblast growth factor, or monocyte chemotactic protein-1 using a transgenic mouse model. Additional purification of differentiated iPS cells and an understanding of the combination of specific cytokines would be a very important factor in the future. 